Кудряшов Владимир Юрьевич

аспирант Московского финансово-юридического университета (МФЮА)

\section{СОЗДАНИЕ ГОСУДАРСТВЕННЫХ ХОЛДИНГОВ. ОБЪЕДИНЕННАЯ СУДОСТРОИТЕЛЬНАЯ КОРПОРАЦИЯ И ОБЪЕДИНЕННАЯ АВИАСТРОИТЕЛЬНАЯ КОРПОРАЦИЯ}

Аннотация:

Во второй половине 2000-х г2. наметилась тенденция создания государственных холдингов. Реструктуризацией государственных активов предполагалось решить проблему неэффективного использования государственного имущества, а также сконцентрировать управленческие ресурсы на разработке стратегии для небольшого числа крупных корпораций. В первую очередь реформирование коснулось предприятий, задействованных $в$ обеспечении обороноспособности Российской Федерации. Результатом деятельности в этом направлении стало создание крупных отраслевых корпораций, главная задача которых заключалась в выполнении гособоронзаказа. В статье описаны предпосылки создания государственных холдингов, а также на примере Объединенной судостроительной корпорации и Объединенной авиастроительной корпорации рассмотрены история 603никновения $и$ итоги деятельности отраслевых госхолдингов. Целями работы являются ознакомление с основными принципами построения государственных холдингов, анализ целесообразности этой деятельности на примере двух корпораций.

Ключевые слова:

государственный холдине, дочернее общество, Объединенная авиастроительная корпорация, Объединенная судостроительная корпорация.
Kudryashov Vladimir Yuryevich

PhD student

Moscow University of Finance and Law

\section{THE ESTABLISHMENT OF STATE HOLDINGS. UNITED SHIPBUILDING CORPORATION AND UNITED AIRCRAFT CORPORATION}

Summary:

In the second half of 2000, there was a tendency to create state holdings in Russia. The state assets restructuration was supposed to solve the problem of inefficient use of state property, as well as focus management resources on the development of a strategy for a few large corporations. First and foremost, the reforms affected enterprises involved in the defense of the country. Thus, the activities in this regard resulted in the establishment of large industrial corporations, whose main task was to implement state defense order. The article describes the prerequisites for the creation of state holdings and discusses the history and results of activities of the industrial state holdings by the case study of United Shipbuilding Corporation and United Aircraft Corporation. The research objective is to show the main principles of constructing state holdings and their feasibility based on the analysis of two corporations.

Keywords: state holding, subsidiary company, United Aircraft Corporation, United Shipbuilding Corporation.

Во второй половине 2000-х гг. в Российской Федерации наметилась тенденция создания государственных холдингов. С 2006 по 2008 г. образованы такие крупные компании, как АО «Объединенная судостроительная корпорация» (ОСК), ПАО «Объединенная авиастроительная корпорация» (ОАК), госкорпорация «Ростехнологии», акционерное общество «Оборонсервис», госкорпорация «Росатом», госкорпорация «Роснано». Причиной активных усилий государства в переходе к данным формам государственного участия в рыночной экономике послужило множество фракторов, из которых можно выделить два основных, оказывающих определяющее влияние на все остальные.

За 1990-е гг. сложилась общая негативная экономическая ситуация: спад производства (индекс промышленного производства во всех отраслях промышленности по сравнению с величиной 1990 г., принятой за 100 \%, к началу 2000-х гг. изменялся так, \%: в 1992 г. - 75, 1995 - 50, 1996 - 47, 1997 - 48, 1998 - 46, 1999 - 51); пиковое значение показателя безработицы в 1999 г. - 14 \%; отсутствие возможности составить конкуренцию иностранным компаниям практически в любой производственной сфере. Опыт зарубежных стран показывал эфффективность создания государственных корпораций в тех отраслях экономики, где частные предприятия на определенном этапе не могли удовлетворить возникающие потребности или же обеспечение таких потребностей частными предпринимателями было убыточно и нецелесообразно. В таких случаях государственная корпорация становилась опорой экономики в создаваемой отрасли и в дальнейшем - ее локомотивом. Примерами подобных организаций могут служить компании, создаваемые в Соединенных Штатах Америки в период кризиса 1930-х гг., а также государственные корпорации, учреждаемые в Европе после окончания Второй мировой войны в целях восстановления национальных экономик. 
Предполагалось, что образование крупных отраслевых корпораций по указанному принципу позволит преодолеть кризисные явления в перестраиваемой экономике России. В отличие от западных примеров, где госкорпорации формировались, как правило, путем национализации, в нашей стране образование крупных госхолдингов происходило в основном за счет реорганизации уже принадлежавших государству активов. Поэтому создание гособъединений должно было решать еще одну серьезную проблему - неэфффективное использование государственного имущества [1].

На первом этапе этого процесса определялись перечни государственных предприятий, обладающих потенциалом для решения поставленных государством задач, а также компаний, которые по тем или иным причинам не вписывались в выработанные схемы реформирования. Сохраняемые в государственной собственности организации преобразовывались в государственные учреждения, акционерные общества, 100 \% акций которых принадлежало власти. Не подлежавшие включению в круг участников крупных холдингов предприятия подлежали ликвидации, приватизации или передаче на другой уровень государственной собственности.

На втором этапе осуществлялось укрупнение сохраняемых под управлением государства предприятий путем слияний и присоединений. Они объединялись в концерны и холдинги, в свою очередь становившиеся основой для формирования крупных корпораций, в капитале которых участвует государство. Одновременно с этим решалась задача сокращения непроизводительной конкуренции между компаниями госсектора.

Сокращение численности самостоятельных государственных хозяйствующих субъектов позволяло сосредоточить управление на определении стратегии деятельности ограниченного числа крупных субъектов, предоставив последним возможности по определению не только собственной тактики, но и стратегии подчиненных им предприятий; а также высвобождении значительных управленческих людских ресурсов в профильных государственных ведомствах. Создаваемые госхолдинги за счет преимуществ не только перед разрозненными государственными предприятиями, но и перед частными компаниями, не имеющими таких ресурсов, могли бы стать мотором для развития как отдельных отраслей, так и всей экономики страны.

Однако вопрос образования подобных холдингов вплоть до настоящего момента является дискуссионным. У данного направления преобразования государственных активов есть и противники. Так, в статье «Создание и деятельность государственных корпораций» И.Ю. Колесник пишет: «Анализ целей создания и деятельности государственных корпораций заставляет усомниться в том, что эти цели при заданных параметрах - правовых условиях и передаваемых финансовых ресурсах - могут быть достигнуты» [2].

Рассмотрим образование государственных холдингов на примере Объединенной судостроительной корпорации и Объединенной авиастроительной корпорации и попробуем разобраться, насколько обоснованно было их создание. Также следует обратиться к итогам их деятельности и ответить на вопрос о целесообразности подобного рода реорганизации государственных активов. Предпосылки создания и в том, и в другом случаях были одинаковыми.

Экономический кризис, связанный с распадом Советского Союза, затронул практически каждую отрасль производства. Следствием уменьшения объемов финансирования в 1990-е гг. в судостроительной отрасли стало значительное сокращение научно-исследовательских разработок. Таким образом, за десятилетие после распада СССР не была создана научная база, необходимая для осуществления перспективных проектов и последующего их внедрения, единичные достижения в данной области не получали достаточного финансирования и в полной мере реализованы не были. Результатами послужили отставание России от ряда зарубежных стран в сорере передовых морских систем, быстрое устаревание военно-морского фрлота и, как следствие, ослабление обороноспособности государства. Снижение количества заказов на строительство всех типов судов привело к сложной экономической ситуации на абсолютном большинстве предприятий. Вследствие этого оборудование не обновлялось в компаниях как самой отрасли, так и смежных секторов, что отрицательно влияло на сроки и трудоемкость производства.

Таким образом, согласно Стратегии развития судостроительной промышленности на период до 2020 г. и на дальнейшую перспективу [3], в основе структурного реформирования данного госсектора лежали следующие основные принципы: первоочередное развитие предприятий, отвечающих за обороноспособность; равнодоступность интеллектуального потенциала конструкторских бюро для всех компаний отрасли; создание оптимальной организационной структуры управления объединением предприятий, обеспечивающей равноправие и заинтересованность в совместной деятельности.

Схожие проблемы наблюдались и в авиационной отрасли. Промышленность этого сектора в СССР была ориентирована на крупносерийное производство гражданской и военной авиатехники. Пассажиропоток и объем грузовых перевозок того времени требовали значительных ежегодных поставок. Военно-воздушные силы Советского Союза, являясь самыми крупными ВВС в 
мире к моменту распада государства, также нуждались в ежегодном обновлении парка летательных аппаратов. Кроме того, высокий уровень качества военных самолетов обеспечивал существенные объемы экспортных поставок.

В начале 1990-х гг. в связи с экономическим кризисом резко сократился объем внутренних авиаперевозок в грузовом и пассажирском сегментах авиатранспорта. Возросший объем международных авиаперевозок осуществлялся в основном за счет зарубежных летательных аппаратов. Существующий парк воздушных судов стал избыточным, что послужило главной трудностью отечественного авиастроения в то время. Как следствие, наблюдалась недостаточная загрузка мощностей. Отсутствие заказов повлекло за собой проблемы оттока квалифицированных кадров, дефицита новых, молодых специалистов.

Кроме того, начавшаяся приватизация государственных предприятий привела к тому, что компании, ранее входившие в одну производственную цепочку от проектирования и разработки до создания конечного продукта, образуя замкнутый цикл, оказались в руках разных владельцев. Система несвязанных, независимых организаций была по сути противоположна прежней структуре авиапромышленности в СССР, имевшей централизованное управление в виде Министерства авиационной промышленности и состоявшей из строго выстроенных цепочек разработки и производства определенных марок воздушных судов. Нарушение этих связей создавало значительные трудности, такие как дублирование функций и отсутствие отлаженной внутриотраслевой кооперации.

Таким образом, главной целью, заявленной при создании Объединенной авиастроительной корпорации, были устранение малопродуктивной конкуренции между разными авиационными предприятиями внутри страны и объединение их усилий для производства продукции, способной конкурировать с лидерами отрасли на мировом рынке.

ОАК и ОСК созданы в 2006 и 2007 гг. соответственно.

В формировании ОСК можно выделить два этапа. На первом из них учреждались следующие акционерные общества: «Объединенная судостроительная корпорация» (г. Санкт-Петербург) - ОСК, «Западный центр судостроения» - ЗЦС, «Северный центр судостроения и судоремонта» - СЦСС, «Дальневосточный центр судостроения и судоремонта» - ДЦСС, $100 \%$ акций каждого из которых на момент учреждения находились в федеральной собственности [4]. В качестве вклада Российской Федерации в уставной капитал указанных компаний вносились находящиеся в федеральной собственности пакеты акций профильных акционерных обществ, а также денежные средства. На втором этапе 100 \% минус одна акция каждого из трех центров судостроения вносились в уставной капитал ОСК в порядке оплаты размещаемых дополнительных акций в связи с увеличением уставного капитала.

ОСК формировалась фрактически по географическому принципу. В результате был образован трехуровневый холдинг: головная компания - территориальные субхолдинги - дочерние хозяйственные общества (ДХО). Государству принадлежат весь пакет акций головного предприятия, а также по одной акции каждого субхолдинга и некоторых ДХО.

По состоянию на 31.12.2015 г. АО «ОСК» включает в себя 4 территориальных субхолдинга (Западный, Северный, Дальневосточный, Южный центры судостроения и судоремонта). В интегрированную структуру ОСК входят 33 дочерних общества (в силу преобладающего участия в уставном капитале таких обществ либо в соответствии с их учредительными документами), 4 зависимых общества и 23 общества, подконтрольных дочерним обществам ОСК [5]. Предприятия объединены в субхолдинги по географическому признаку (рисунок 1).

Структура ПАО «ОАК», представленная на рисунке 2, в отличие от рассмотренной структуры ОСК не имеет четкого разделения на субхолдинги и дочерние хозяйственные общества. Это объясняется тем, что ОАК образована посредством вливания в холдинг подавляющего числа компаний, в которых помимо государственного участия присутствовали частные акционеры. Структура акционерного капитала предприятий холдинга получилась довольно громоздкой, сложной и запутанной. Кроме указанных обществ, ОАК как управляющая организация, которой переданы полномочия единоличного исполнительного органа, осуществляет управление 15 авиаремонтными заводами (АРЗ), входящими в холдинг «Гарнизон».

Итогами деятельности холдингов можно назвать устойчивый рост основных финансовых показателей по состоянию на конец 2015 г., а также укрепление позиций России в судостроительной и авиастроительной областях на мировой арене. За время существования судостроительной корпорации Россия вышла на первое место по поставкам военно-морской техники (16 \% среди мировых поставщиков боевых кораблей в водоизмещающем исчислении) и поднялась на седьмую позицию по объему экспортных поставок кораблей и судов, исчисленных в единицах. В авиастроительной отрасли в 2015 г. ОАК поставлено отечественным и зарубежным заказчикам 156 самолетов, что в 1,5 раза больше по отношению к цифрам 2011 г. [6]. 

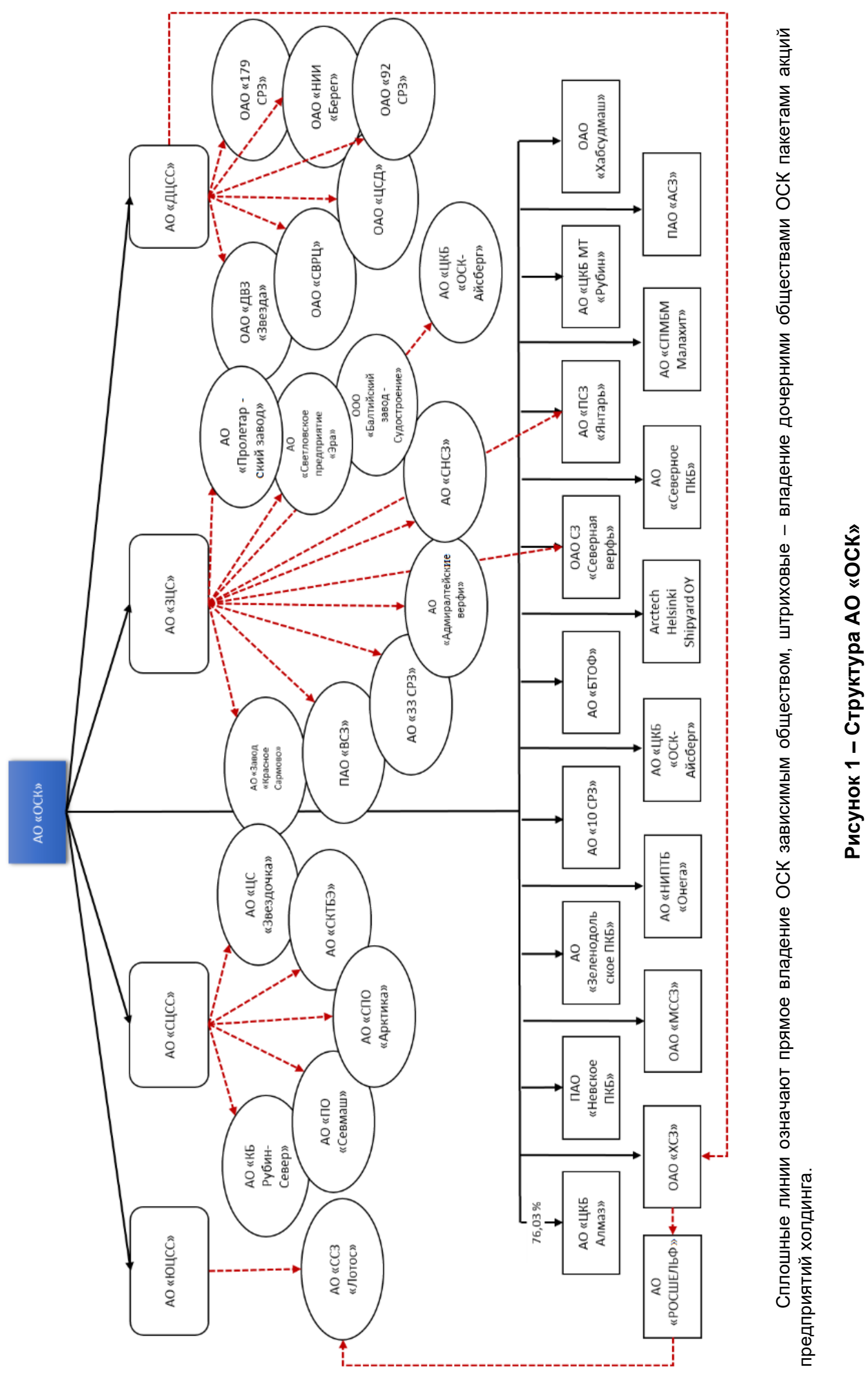


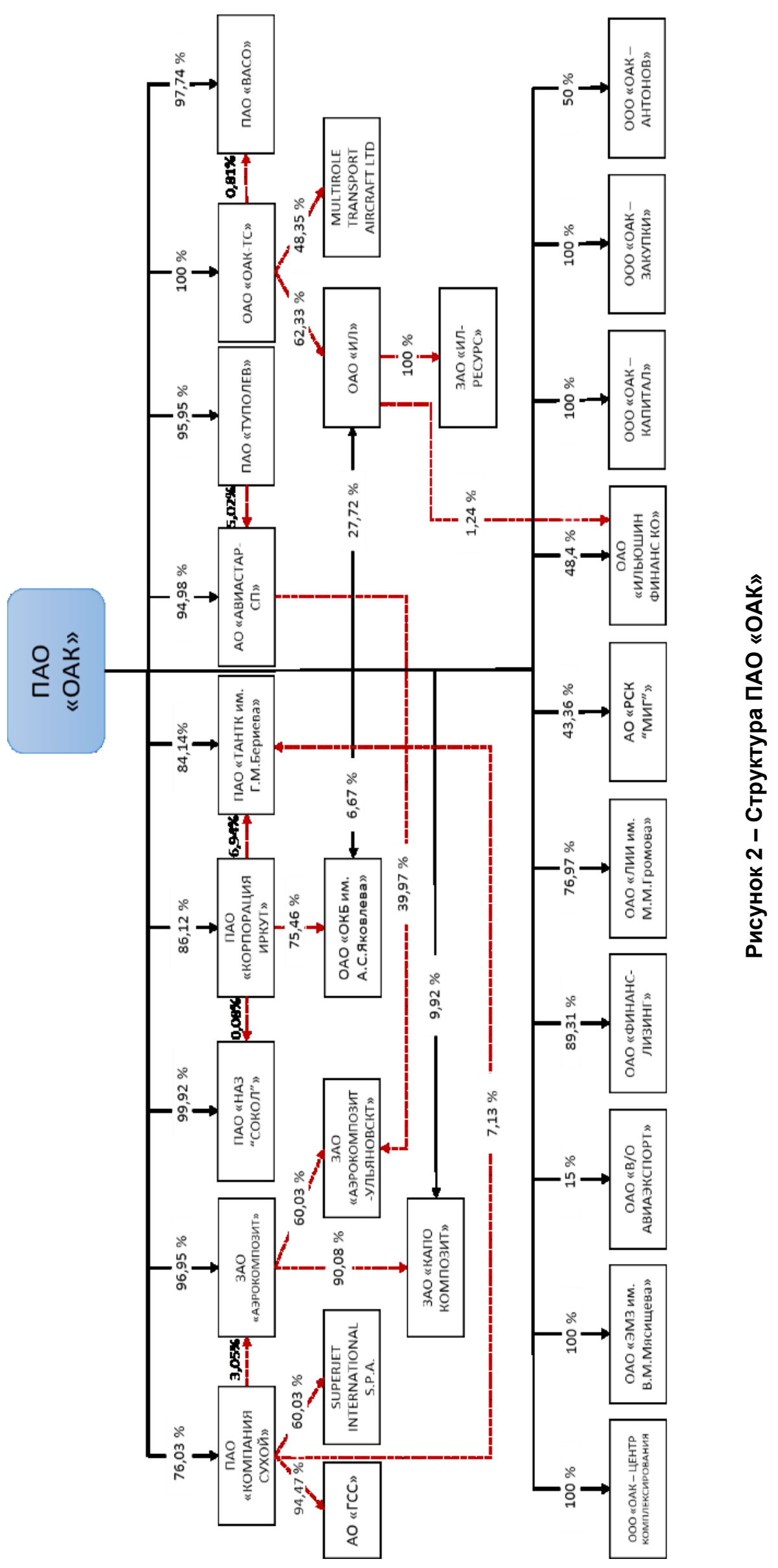


Приведем сравнительные данные главных финансовых показателей двух холдингов на основании значений, указанных в годовых отчетах за 2015 г. (таблицы 1, 2). К этому году размер выручки по ОСК увеличился на $61 \%$, показатель чистой прибыли - более чем в 5 раз, что положительно сказалось на величине чистых активов холдинга - повышение на 9 \%. Прибыль ОАК по итогам 2015 г. возросла на 19 \% и достигла 352 млрд р. - это наибольший показатель за всю историю корпорации.

Таблица 1 - Финансовые показатели холдинга ОСК за 2013-2015 гг. [7]

\begin{tabular}{|l|c|c|c|c|}
\hline \multicolumn{1}{|c|}{ Показатель } & $\mathbf{2 0 1 3}$ & $\mathbf{2 0 1 4}$ & $\mathbf{2 0 1 5}$ & $\begin{array}{c}\text { Относительное } \\
\text { увеличение к } \\
\mathbf{2 0 1 3} \text { г., \% }\end{array}$ \\
\hline Выручка, млн р. & 188620 & 260769 & 304386 & 61 \\
\hline Чистая прибыль, млн р. & 3876 & 11409 & 20708 & 434 \\
\hline $\begin{array}{l}\text { Среднесписочная численность пер- } \\
\text { сонала, чел. }\end{array}$ & 75532 & 77766 & 82652 & 9 \\
\hline Стоимость чистых активов, млн р. & 138706 & 139217 & 164695 & 19 \\
\hline
\end{tabular}

Таблица 2 - Финансовые показатели холдинга ОАК в 2011-2015 гг. [8]

\begin{tabular}{|l|c|c|c|c|c|}
\hline \multicolumn{1}{|c|}{ Показатель } & $\mathbf{2 0 1 1}$ & $\mathbf{2 0 1 2}$ & $\mathbf{2 0 1 3}$ & $\mathbf{2 0 1 4}$ & $\mathbf{2 0 1 5}$ \\
\hline Выручка, млрд р. & 161,7 & 171,0 & 220,1 & 294,5 & 351,8 \\
\hline Валовая прибыль, млн р. & 50,3 & 35,9 & 43,4 & 45,2 & 44,5 \\
\hline $\begin{array}{l}\text { Среднесписочная численность персонала, тыс. } \\
\text { чел. }\end{array}$ & 92,6 & 92,4 & 94,0 & 98,8 & 101,4 \\
\hline
\end{tabular}

В 2013-2015 гг. операционная деятельность ОАК характеризовалась устойчивым увеличением поставок (среднегодовой темп прироста 19 \%) и объемов продаж (среднегодовой темп прироста выручки 26 \%). ОАК входит в число ключевых игроков мирового рынка гражданского и военного самолетостроения. Конкурентами корпорации выступают ведущие мировые производители авиатехники, включая Airbus Group, Boeing, Embraer, Bombardier, Lockheed Martin.

В заключение приведем слова президента ОСК А.Л. Рахманова: «Наша главная цель - создать на базе АО "ОСК" управляющую компанию, которая будет являться центром принятия основных решений в отрасли. Мы планируем централизовать ряд ключевых функций: речь идет и о финансах, и о функции управления персоналом, и о материально-техническом обеспечении, капитальном строительстве, инжиниринге и т. д. Задача именно в том, чтобы из относительно разрозненных предприятий, которые были вполне успешно интегрированы под "зонтиком" АО "ОСК", создать эффективно работающую машину» [9]. В равной степени эти слова можно отнести и к ОАК с некоторой поправкой на отрасль.

Таким образом, отвечая на поставленный в начале работы вопрос, можно сказать, что рассмотренные компании представляют собой положительный пример создания государственных холдингов. Первоочередные поставленные перед корпорациями цели - развитие предприятий, отвечающих за обороноспособность, устранение непродуктивной конкуренции в отраслях, конкурентоспособность на мировой арене - достигнуты. Достижение обозначенных результатов неинтегрированными под управление головной организации производств возможно при затрате значительно большего объема управленческих ресурсов.

\section{Ссылки:}

1. Gershman M., Thurner T. New development: State-owned enterprises as powerhouses for innovation - the Russian case // Public, Money \& Management. 2016. No. 4. P. 297-302.

2. Колесник И.Ю. Создание и деятельность государственных корпораций // Контуры глобальных трансформаций: политика, экономика, право. 2009. № 2. С. 85-109.

3. Стратегия развития судостроительной промышленности на период до 2020 г. и на дальнейшую перспективу [Электронный ресурс] : утв. приказом Минпромэнерго России от 6 сент. 2007 г. № 354. Доступ из справ.-правовой системы «КонсультантПлюс».

4. Об открытом акционерном обществе «Объединенная судостроительная корпорация» [Электронный ресурс] : указ Президента РФ № 397 от 21 марта 2007 г. URL: http://kremlin.ru/acts/bank/25217 (дата обращения: 10.07.2017)

5. Смотрим за горизонт [Электронный ресурc] : годовой отчет AO «ОСК» за 2015 г. URL: http://www.oaoosk.ru/upload/iblock/456/godovoy-otchet-ao-osk-2015.pdf (дата обращения: 10.07.2017).

6. Годовой отчет ПАО «ОАК» за 2015 г. [Электронный ресурc]. URL: http://www.uacrussia.ru/upload/iblock/9f7/9f75116a14cbf261765bf4e1cc849335.pdf (дата обращения: 10.07.2017).

7. Смотрим за горизонт.

8. Годовой отчет ...

9. Там же. 


\section{References:}

Gershman, M \& Thurner, T 2016, 'New development: State-owned enterprises as powerhouses for innovation - the Russian case', Public, Money \& Management, no. 4, pp. 297-302, https://doi.org/10.1080/09540962.2016.1162996.

Kolesnik, IYu 2009, 'Creation and activity of state corporations', Kontury global'nykh transformatsiy: politika, ekonomika, pravo, no. 2, pp. 85-109, (in Russian). 